\title{
THE EXPERIENCE OF RUSSIAN COMPANIES IN SWITCHING TO REMOTE WORK IN THE CONTEXT OF THE PANDEMIC
}

KLIMOVA, Svetlana G., Cand. Sc. (Philosophy), Leading Research Associate at the Institute of Sociology of the Federal Research Sociological Center of the Russian Academy of Sciences (sgklimova@mail.ru); KLIMOV, Ivan A., Cand. Sc. (Sociology), Associate Professor at the Social Sciences Department and Senior Researcher at the International Laboratory for Applied Network Research, National Research University 'Higher School of Economics' (NRU HSE); Senior Researcher at the Institute of Sociology of the Federal Research Sociological Center of the Russian Academy of Sciences (iklimov@hse.ru). Both are in Moscow, Russia.

\begin{abstract}
This article presents the results of a study of the experience of the emergency transition to remote work in Russian organizations and enterprises in the spring of 2020. The main purpose of the study is to analyze how the lockdown has changed the strategies of managing teams: how managers determined the most pressing tasks and what technical capabilities, organizational and communicative techniques have been used to solve them. The transfer of employees to remote work entailed a decrease in the efficiency of collective work with an increase in the amount of working time; people's concerns about the stability of their work; difficulties in business interaction. Those companies that had created IT-platforms and communication channels before the lockdown managed to solve production problems relatively quickly. But the problems of motivation, engagement, trust, mutual understanding, etc. could not be solved promptly. The crisis was relatively successfully passed by those organizations that already had these skills in their corporate culture repertoire. Experience in overcoming the difficulties of the lockdown has shown that effective work outside the office is possible if managers use solutions that motivate employees to show initiative and cooperate, to find the optimal balance between control and trust. As a consequence, there appeared a demand for a corporate culture involving horizontal interaction, a combination of stability and variability of communication rules, and feedback tools.
\end{abstract}

Keywords: lockdown $\bullet$ remote work $\bullet$ IT-systems $\bullet$ work time $\bullet$ business communication $\bullet$ corporate culture $\bullet$ cooperation $\bullet$ motivation $\bullet$ engagement $\bullet$ trust

DOI: $10.31857 / S 013216250016777-7$

This article is a translation of: Климова С.Г., Климов И.А. Опыт перехода российских компаний на удаленную работу в ситуации пандемии // Sotsiologicheskie Issledovaniia. 2021. No 7: 50-60. DOI: $10.31857 /$ S013216250014470-0

Relevance of the Topic. The mass emergency transfer to remote work in the spring of 2020 led to serious changes in the activities of companies and in employees' perceptions of concepts such as office, workplace, working hours, and work team. The scale and nature of the changes are shown by data of the Russian Public Opinion Research Center (WCIOM). As of May 2020, 40 per cent of Russian workers had not changed their work mode. By June, another 9 per cent had returned to their workplaces. Forty-nine percent of state-paid workers and almost as many (53 per cent) of commercial workers continued to work at their regular workplaces. In the spring of 2020, approximately three-quarters of skilled and unskilled workers and one-third of university degree professionals in both the commercial sector and budget-funded organizations remained at their workplaces ${ }^{1}$.

${ }^{1}$ Expanded collection of WCIOM data for the thematic issue 'Trud i zanyatost" [Labor and Employment] (No. 1). 2020. P. 56. URL: https://wciom.ru/fileadmin/file/nauka/podborka/rasshirennaya_podborka_dannyh_ wciom.pdf (accessed on February 12, 2021). 
May 2020 saw an increase in the number of workers sent on unpaid leave; cases of workers' transfer to shorter working hours, a part-time working week at the initiative of the administration became more frequent ${ }^{2}$. Accordingly, earnings decreased. According to an Internet poll conducted by V. Gimpelson and R. Kapelyushnikov, 40 per cent of workers mentioned a reduction in wages in May $2020^{3}$. At the same time, in a critical situation, some employment problems were more or less smoothed out and compensated by joint efforts of workers and managers. The WCIOM data show that the general problem of the pandemic forced everyone to enlist the efforts and to solve even those problems of labor relations and work organization that had not been solved before or had not been solved in full. The disorganization in the spring of 2020 turned out to be short-lived. By the summer, the labor situation had either returned to its pre-Covid norm by some parameters or even improved somewhat. In particular, the number of mentions of wage arrears did not increase; workers were less likely to mention the threat of mass layoffs and conflicts with the administration and other workers ${ }^{4}$.

The spring 2020 situation was captured in a study conducted by online interviews from April 3 to May 20, 2020 about the challenges that executives had to address in order to keep their companies operational ${ }^{5}$. The focused semi-structured interview included a discussion of five topics: 1) What did respondents do in relation to the transition to telecommuting? 2) What barriers and challenges have arisen in the process? 3) How do executives view the company's digitalization strategy for business processes? 4) How are the company's employees coping with adapting to the new environment? 5) How do executives see the future of their company and what employment strategy are they choosing in the context of the pandemic? The interviews lasted from 30 minutes to 1.5 hours. Our research aimed to understand: a) how executives changed their company's business processes to minimize the economic and social impact of the spring 2020 lockdown; b) what strategy in work organization and labor relations they chose; and c) what managerial lessons were learned from the experience of the emergency transition to remote work. The objectives of the study included questions about the organization of interaction and communication in work collectives that switched to remote work; about difficulties and their overcoming; about ways to compensate for losses; about the features of corporate culture that were most in demand in the remote work situation.

In our view, the relevance of these issues is not limited to the lockdown situation not only because remote work is spreading to an increasing number of non-emergency jobs, but also because this crisis has revealed problems in labor relations that existed before but were not so pronounced.

Problems caused by remote work. The main problem had to do with the fundamental possibility to preserve the workforce and the business as a whole. Periodic upheavals in the global markets and in the domestic economy have formed a set of ideas among company executives about the repertoire of possible actions during a crisis: 1) to keep the whole team or the most valuable employees, despite financial difficulties ['We do not lay off anyone; we want to keep the

2 Ibid. P. 69.

${ }^{3}$ Gimpel'son V., Kapelyushnikov R. Rynok truda pod natiskom koronavirusa. Tsentr trudovykh issledovaniy VShE [Labor market under the onslaught of coronavirus. Center for Labor Research of the Higher School of Economics]. 2020. P. 1. URL: https://www.hse.ru/mirror/pubs/share/369698959.pdf (accessed on February 2, 2021).

${ }^{4}$ Expanded collection of WCIOM data for the thematic issue 'Trud i zanyatost" [Labor and Employment] (No. 1). 2020. P. 58. URL: https://wciom.ru/fileadmin/file/nauka/podborka/rasshirennaya_podborka_dannyh_ wciom.pdf (accessed on February 12, 2021).

${ }^{5}$ The study was supported by the Ward Howell Talent Equity Institute (I. Klimov). Managers of 114 companies belonging to large (34) and medium (80) businesses took part in the survey. There were 47 regional companies, and another 8 were Russian representative offices of international corporations. Our interviewees represented the following sectors (the number of companies is given in brackets): retail (16), IT and telecom (12), manufacturing (8), pharmaceutics (6), services and entertainment (8), oil and gas (5), financial services (6), food industry (4), as well as development and construction, transport and logistics, agricultural production, media, education, etc. In addition, it was possible to discuss the situation with representatives of three state organizations belonging to the general federal structure and the regional administration. 
team to work after the quarantine. We promote the best trainers in the networks so that they could find clients for online classes. They keep the money they earn'] $(1)^{6}$; 2) to fire / send employees on unpaid leave ['We wanted to measure KPI on whether it was necessary to have such a large number of employees. Covid forced it'] (2); 3) to make remote work permanent, while reducing the number of employees ['We're interested in using more remote telecommuting for office work and saving up to 15 per cent. It is interesting to achieve such savings'] (3).

The decision to retain the team as much as possible while allowing for a forced reduction in wages is considered optimal by most of the interviewed managers. Experts interviewed by the Public Opinion Foundation also say that this decision is typical and has been tested by previous crisis situations. Job cuts and layoffs are considered more radical and less acceptable solutions (Sotsiologiya pandemiyi [Sociology of the Pandemic]), 2021: 192, 256].

The basic condition for preserving the work force, or at least its core during the lockdown was the availability of information platforms. 'All the top managers are very happy with IT; it was even a surprise how well it worked. But now we need to decide on the production. Now we have to solve the issue of sleeping quarters at work if people can't leave, and a canteen' (4). Accordingly, those companies that did not have IT systems ready were forced to lay off employees and close down. 'There was no platform, and nothing was ready for this turn of events. Key employees could not be transferred to remote work. It was not possible and will not be possible to replace the face-to-face part of the negotiations with a remote one. Everyone was offered to quit their jobs in order to receive unemployment benefits' (5).

At the same time, the experience of urgent transfers of many employees to remote work has shown that the efficiency of IT systems alone is not enough. There are other important components such as redesigned business processes, a set of support services, a system of operational performance indicators, internal regulatory documentation, control and safety. Those organizations that even earlier created tools for the organization of distributed work, remote development, and decision-making, coordination of documents, monitoring and evaluation of the effectiveness of work, and occupational safety did not face great problems from the transition to remote work. But the existing technical and technological systems have not solved all the problems of effective work in the remote environment.

According to the interview materials, working remotely turned out to be a 'stressful field experiment' for the heads of organizations, which showed the viability of the rules and management practices that determine the order of interaction between employees. 'We work like at war, and this reveals all our ills and shortcomings and creates new ones' (6).

The number of personnel management tasks in companies increased dramatically. It was necessary to quickly devise and implement all kinds of solutions: at any cost to keep some employees working, fire others, organize self-isolation for risk groups; ensure hygienic conditions for those who continued to work at their workplaces in a company, a construction site, a store, etc.; change pay schemes, and many other things.

Managers acknowledged that work in the remote format was less efficient, but they were not always ready to articulate the cause and, consequently, the solution to this problem. Those who did find such formulations spoke of old problems actualized by the extraordinary situation. 'There is no such thing as remote self-organization. You can't just transfer offline techniques to online. Something stops working. The reason is obvious: communication failures, weak control and insufficient involvement of people' (7).

Based on the interviews, we have identified three main problem areas and, accordingly, three basic conditions for successful telecommuting. 1) Organizational: a clear scheme of interactions, business communications corresponding to the technology of the production process. 2) Managerial: skills of working in a 'flexible' team, 'teaming' competences, stimulation and control. 3) Socio-psychological: specific features of corporate culture: mechanisms of motivation, involvement, trust, and effectiveness support.

\footnotetext{
${ }^{6}$ The number in brackets indicates the number in the list of cited authors (see the appendix to the paper).
} 
Organization of interactions and business communications. Interaction between employees; coordinating the efforts of workers on the job (in the office) and those transferred to work remotely are the topics that executives mentioned above all when talking about their managerial efforts during the initial lockdown period. '.... In the evening - 'in the paper', and in the morning we already have to work everything out! HR people turned out to be one of the key tools in the crisis. They have to know and understand the business, see the social situation inside the company and keep in touch with the employees. They should combine an understanding of the business processes and the current economic situation in a crisis. We send risk groups to isolation, provide them with food, and those who are working need to be protected and their temperature needs to be measured. We hire people, and we have to teach them quickly and see how they adapt. And constantly we need to understand what worries people, everyone's fears and overloads' (8).

This statement means that the organization of distributed work is not only a conveyor belt of functions. Most of today's production processes are primarily business communications information exchange, meetings, and negotiations. Routine management tasks in the remote mode have gained newfound relevance, have become imperative because there have appeared 'gaps' in communication. For example: the context of a message is understood incompletely or incorrectly; meanings are reinterpreted; messages are delayed or arrive at the wrong address; the significance of this or that element of a business situation is subjected to arbitrary interpretations, etc ${ }^{7}$. Even those companies that were aware that these problems would escalate did not manage to avoid communicative failures. Their causes in the situation of online communication are objective difficulties and the lack of specific skills that participants in online discussions could not acquire overnight. Objective difficulties arise from the lack of important elements of background knowledge of the work situation and poor working conditions at home. Specific problems that arise in the situation of online communication are the lack of communicative skills in formulating short and clear messages; inadequate or incomplete understanding of the partner; improper ascription of meanings of statements, etc. [Shirokikh, 2016: 89-90]. In the situation of personal communication these problems are largely compensated by background knowledge drawn from diverse and often informal sources; the use of nonverbal means of communication; less rigid time and normative regulation of business discussions.

Executives in their interviews mentioned only the most acute problems of online communication. These are, first, the difficulties caused by the lack of the right conditions for working at home. Executives were obviously proud of their willingness to create such conditions. '<Our IT-company> gave employees ten days to arrange a work environment at home. After all, it's clear that there are household activities and kids and cooking and things like that. People need to learn to survive together in a confined space, to adjust their routines. Stress, fear, and burnout are worse than idle time' (9). Following the workers, managers moved their working stations to their homes. 'Wherever you are, we'll bring you your workspace, too. Many don't even have chairs at home, and the employee's back is, in effect, a working tool' (10).

Second, communication failures were due to problems with temporal synchronization of actions. 'The main difficulty is organizing synchronization between units and within units. <This> problem was solved by organizing an operational rhythm of meetings: we introduced daily checkup meetings' (11). Thirdly, managers were overloaded, and so they could devote less time to interaction with their subordinates. This sharply reduced the quality and efficiency of business communications. 'Production and logistics are overloaded. The difficulties which I consider very serious are overloading of managers. It takes a lot of effort to maintain communication internally, and it still happens to be insufficient' (12).

The reasons for communication failures are not limited to those mentioned in the conversations. Obviously, the topic of business communication in the remote work environment requires reflection and development of specific procedures and skills on the premise that this practice will become widespread.

\footnotetext{
${ }^{7}$ For the processes of encoding and decoding messages in communications, see [Hall, 2001].
} 
The technology of business communications is the most obvious, but not the only problem of organizing teamwork in telecommuting. It follows from the materials of the interviews that a wide range of issues related to corporate culture proved to be relevant. Topics that previously seemed secondary in the nomenclature of managerial competences turned out to require operationalization and immediate solution. The question of which aspects of corporate culture have become much needed in the remote work situation is interesting, because it shows not only the situational, but also the stable significance of the mentioned elements. As can be seen from the materials of the interviews, the ideas about proper (acceptable, desirable) behavior in hierarchical and horizontal business interactions took on increasing importance in the first place. Difficulties started to appear due to the absence or uncertainty of important elements of the corporate culture: norms, mutual expectations, everyday practices manifested in teamwork skills; leadership competencies, trust and involvement. Let's note the skills that were most frequently mentioned in the interviews.

Ability to work in an 'agile' team, 'teaming' competencies, leadership. IT-companies spent no time on 'expanding' the bandwidth of platforms and communication channels. It was only natural that they were able to do this 'almost instantly': 'In the morning of the next day, it still did not work, and by lunch everyone was able to work' (13). Quite quickly they formulated the tasks of mobilizing teamwork skills (the so-called teaming competencies) that previously existed in the background ${ }^{8}$. 'We realized pretty quickly that we absolutely needed team feedback. This is not just migration of projects to a remote location, but also an increased workload, and this overlaps with a host of other problems, intertwining the family, personal and work <issues>. That's why we use different methods of work - from conversations with 'team leads' and game surveys to informal online gatherings once a week in the evenings,- we bring in psychological support' (10).

It seems that not everyone was able to change over to remote work so quickly and successfully. Some of our interlocutors (6 companies - IT, telecom, e-commerce, education, delivery services) admitted that when organizing remote work, the efficiency of both individual employees and the company as a whole was noticeably reduced, while the workload increased unnecessarily. Judging by the interviews, the difficulties were caused, along with technological circumstances and defects in the organization of collective work in the remote mode, by the immature work culture in distributed teams; ${ }^{9}$ unpreparedness of employees and managers to interact exclusively online.

The number of short, informal meetings and conversations between employees declined while working remotely, so there appeared a feeling of detachment from what was happening in the company. The rituals of working together in the office - briefings, setting tasks, coordinating project work - 'fell into abeyance'. 'It turned out that online cannot fully replace the many functions of offline rituals - uniting, engaging, and motivating. And they are just as important for executives as they are for <ordinary> employees' (14).

Executives who demonstrated a willingness to take on full leadership quickly mobilized their competencies. Tools for organizing distributed work, decision-making, document coordination, management and assessment of performance were complemented by a set of diverse practices based on soft skills ${ }^{10}$. And this combination of managers' willingness to take responsibility and simultaneously delegate initiative helped greatly in supporting employees and maintaining a 'positive attitude and teamwork' (a collaborative atmosphere). In this respect, companies were quite creative: they introduced surveys as a feedback tool; organized evening small talks with different members; initiated informal horizontal communication and acquaintances; launched 'challenges'

${ }^{8}$ The concept of 'teaming' was suggested by Amy Edmondson to denote teamwork, collaboration aimed at solving a specific task and achieving a specific result without excessive immersion in 'team-building' [Edmondson, 2012].

${ }^{9} \mathrm{~A}$ distributed team is a group of employees physically based in different locations and working on a common task within a single business process.

${ }^{10}$ Soft skills are 'flexible skills' that are related not to basic professional knowledge and experience, but rather to the ability to organize teamwork, conduct transactions and negotiate with colleagues, creativity, ability to learn and adapt to changes. 
(in this case, the initiative-call to solve a problem); analyzed the level of employees overtime and helped them individually build an acceptable 'life-work balance'. 'In the canteen, there was a practice of coming up, getting to know each other, and chatting over lunch. Online, too, 'coffee talk' was organized - first you fill out a small questionnaire, then during your break you are randomly offered an interlocutor for a casual conversation' (10) (a large IT company).

As a special competence related to the organization of collaboration and remote work demanded by the situation, managers mentioned the themes of trust and group involvement. Most often, respondents named two obstacles: the prevalence of 'vertical' relationships in teams to the detriment of horizontal ones and the desire for greater control over the actions of employees. Taken together, this undermines the foundations of trust between employees and managers, creates a sense of uncontrolled development of the situation and distorts mutual expectations. As a result, the group involvement of employees is weaker than it would be necessary in the conditions of the objective impossibility of strengthening control.

The need to build trust for successful telecommuting was talked about in practically all the interviews: 'Trust is a very important factor; trust is the basis of an effective team. This is a great additional burden on the team leaders. It's on them that the feeling of collaboration, common work, and support depends' (15). The trust theme was seen by the respondents as an alternative managerial task with regard to control. But what business tasks and managerial problems the leaders had in mind when they talked about trust was not quite clear. Sociological concepts analyze the trust theme in terms of the idea of the basic need of people in long-term relationships based on generally recognized values, which help predict the development of events in joint actions [Seligman, 2002: 8]. In addition to the value component, there is also a cognitive component to the trust theme. This was mentioned by A. Schütz when he described the mechanisms of the emergence of common meanings in interpersonal interaction. He claimed: 'Any forms of social interactions are based on previously described constructs relating to understanding of the other and patterns of action in general' [Schütz, 2004: 24]. Knowledge concerning tools, procedures, social institutions, customs, and symbolic systems presupposes similar knowledge in other people and determines behavior. Accordingly, 'the task of philosophical sociology is to study the modifications to which common or similar systems of relevance are subjected' [Schütz, 2008: 87]. The third component of the trust theme is emotive. J.T. Toshchenko draws attention to the fact that the result of interaction is not only joint understanding of the meanings of events and actions, but also joint experience: sensual and emotional assessments of social processes and natural phenomena [Toshchenko, 2016: 8]. E. Giddens introduced two other distinctions in the trust theme: trust in institutionalized personal ties and 'trust in abstract systems' [Giddens, 1990: 114, 119, 120].

Our respondents, when talking about trust issues in the context of remote work, more often had in mind trust in institutionalized personal relationships. The interviews highlighted relationships based on trust between managers from different companies, and relationships between employees, managers, and subordinates within a company. Trust-based interactions between different companies became fast and widespread and proved to be effective. Moreover, these interactions were a prologue to the formation of professional communities. Informal assistance in an emergency situation has, in some cases, acquired the status of a sustainable practice based on formalized agreements. This is what our informants and respondents of the Public Opinion Foundation [Sociology of the Pandemic, 2021: 203-205] say. Practices of cooperation between companies based on 'gentlemen's agreements' include cooperation between companies on mutually complementary functions much needed in the pandemic situation; exchange of personnel; creation of professional communities for joint projects; interregional cooperation of professionals; solidarity actions in defense of common interests.

Judging by the interview materials, the relationships of cooperation based on trust are not so smooth between employees and management inside companies. Our interviewees described situations in their companies and talked about a lot of signs which evidenced 'cultural conflicts', 'lack of maturity' of employees, their insufficient self-reliance, responsibility and 
initiative. On the other hand, the interviews revealed much evidence to the effect that managerial practices, too, did not always pass the test of remote work complicated by epidemic and self-isolation. 'Line managers have begun to 'tighten screws', turn on total control and surveillance, so we have to train them in feedback and performance management of subordinates. We didn't realize this so acutely before' (16).

As the interview materials show, trust in the primary labor collectives (work teams) within a company was undermined mainly by managers' doubts about the discipline of employees. 'The technical platform is all good. Remotely everything is great. But the managers are not ready. They have a feeling that it is difficult to control the employees' (17).

We do not know how much these doubts were justified. Perhaps the reason could be found in the previous facts of violations of labor discipline, or perhaps the problem was in the limited repertoire of managers' competences, in particular in the lack of team management skills other than control. Since our respondents were chief executives, they sometimes made it a duty for line managers to trust their subordinates. 'Not all employees were willing to selforganize, and there was low discipline, hence there was anxiety, low mood and decreased effectiveness. We saw unpreparedness of line managers to trust their employees; there is a skew toward hyper control' (16).

The correlation between the functions of control and motivation based on trust is one of the 'eternal' questions of effective personnel management. One of our interlocutors articulated the duality of the task at hand quite succinctly: 'You need to have a lot of discipline and learn to trust employees. You need a good mix that will keep up team dynamics and synergy' (2). In our view, this is the main challenge of today's crisis: we need to reconsider the basis of trust and the tools with which it is achieved.

The rush transfer to remote work showed the urgency of this dilemma, but in the interview materials we did not see examples of solutions. It seems that the executives were not ready to present them. Their education, life, and professional experience, the trend of the post-Fordist ideology of personal competition as an alternative to the archaic Soviet collectivism did not provide the knowledge of how to trust employees and still achieve effectiveness. 'The discussion about employee control has taken a new turn. How to provide not just a comfortable digital workplace, but how to communicate, how to stay in the processes of the company. Management has always been in favor of control. Now the coronavirus has created a unique situation. Employees are tolerant of experimentation and open to collaboration' (6).

The interview materials suggest that the shift from the concept of impersonal functionality to a 'human relationship' based on cooperation and trust does not raise suspicions of manipulation and probably meets the employees' expectations. Attention to employees and their opinions and assessments has been found to have a multiple effect, both for business results and people's moods, and brings personal satisfaction to the manager. 'Every week I hold a teleconference with the entire company and feel how much it gives the employees and me. It begs the question - why didn't I do this before telecommuting?' (17).

Reflecting on the crisis experience and prospects for online work An analysis of the urgent and mass transition to online work in the spring of 2020 showed that remote work may well be a regular part of the employment relationship. While earlier it seemed a very distant task that was difficult to implement, a year later remote working (with its pros and cons) has become a fact of corporate life. The "space of the possible" has greatly expanded. Both the initial and subsequent experience of living and working under quarantine restrictions allows us to draw several conclusions and generalizations.

1. The experience of remote work, caused by the pandemic emergency, has shown that this practice is viable for many types of work. At the same time, remote work has proven not to be quite 'good', since it is associated with stress caused by the fear of stability of one's position and status prospects; difficulties in business interactions; combining work and home affairs, worries about one's physical health and material well-being. The potential of telecommuting can be realized if the fears and negative experiences of both managers and employees are transformed 
into positive and mutually acceptable solutions, and if perceptions of the 'extraordinariness' of the current situation will give way to technical algorithms for effective work outside the office.

2. Remote work became a catalyst for new requests for work and labor relations. In particular, it helped bring up to date the values associated with informal collectivist relations at work (team feedback), which previously seemed to be a dispensable and even archaic management task, contrary to the 'modern' principle of personal competition (for example, ratings or other symbolic status signs). These requests can be situational, appropriate in the event of upheavals (e.g. a decision to keep the staff as much as possible while allowing for a forced wage reduction), but also longterm ones oriented to cooperation and collaboration, horizontal interaction when solving complicated production tasks (for example, group work on autonomous projects). This task is especially important for companies engaged in business development or innovative activities.

3. The remote work experience stimulated the concerns of many workers regarding the threat of unstable employment. These concerns were largely allayed by Law No. 407-FZ, which came into force on January $1,2021^{11}$. Amendments to the Labor Code equalized the concepts of 'distant' and 'remote' work. The Law provides for three forms of distant work: permanent one stipulated by the terms of employment; temporary (forced transfer to distant work at the initiative of the administration in the event of a natural or man-made accident or epidemic); and periodic, if an employee works both in and out of the office (Art. 312 of the Labor Code).

4. Although managers have often talked about the need to find a balance between control and trust, this idea has not become dominant. Executives fear losing the ability to effectively manage employees and are contemplating more or less extensive systems of digital control. By implication, we can conclude that employees, too, often lose adequate insight into the intentions of managers, their motivation and vision of the current situation, as well as of the situation of the company as a whole. The crisis seems to aggravate the conflict between the different dominants of corporate culture. It is not only stability vs. variability, but also hierarchy vs. flexibility; competition vs. cooperation, control vs. responsibility. We can say that in many Russian companies a large-scale experiment with forms of distant work will prompt a rethinking and reinstallation of the 'grounds of trust' on which the interaction between employees and managers is based. In the near future we will see that the correlation between control practices and practices of initiative and self-organization of employees will be rethought and redefined. This redefinition is not directly related to the situation of remote work, although stimulated by it. The mass transition of employees to telecommuting has formulated the task of finding a balance between offline and online management tools. There is a growing confidence in the need for special managerial competencies for organizing teamwork and maintaining the value and normative framework of effective teams: motivation, involvement, trust, stimulation of initiative and development of horizontal ties.

5. The practical tasks of information exchange in a teamwork situation can be solved on the basis of modern sociological concepts. In particular, M. Castells has shown that in network communities, power as an organizing principle does not disappear. But its nature changes significantly. Attributes and symbols of status and hierarchy (office, suit, or car) become less and less visual, visible and effective. Efficiency goes to leadership, horizontal interaction, a combination of stability and variability of communication rules, and feedback tools [Castells, 2011]. These observations are applicable to describe the relation between the dominants of corporate culture and the performance of distributed teams when working remotely. Corporate culture is either a barrier or a good resource for unlocking the potential of distributed and remote work. Effective remote work "doesn't feel good", as one of our interviewees put it, in a system of rigid hierarchical relationships. It requires different principles of leadership and subordination, initiative and responsibility.

${ }^{11}$ Law No. 407-FZ 'On Amendments to the Labor Code of the Russian Federation Regarding Regulation of Distant (Remote) Work and Temporary Transfer of an Employee to Distant (Remote) Work at the Initiative of the Employer in Exceptional Cases'. URL: https://rg.ru/2020/12/11/udalenka-dok.html (accessed on February 12, 2021). 
APPENDIX

\section{Information about the status of respondents whose statements are quoted in the article, in order of first citation}

(1) General Director, owner. Regional network of fitness clubs represented in several regions (except Moscow and St. Petersburg).

(2) Commercial Director. All-Russia company. Non-product retail, building materials.

(3) HR Director. Large all-Russia company. Non-product retail, electronics.

(4) HR Director. Large all-Russia company. Oil and gas sector.

(5) General Director of the regional division of the company. Audit service.

(6) Deputy General Director, Network Development Director. Large all-Russia Company. Food retail.

(7) Deputy General Director. Russian IT company, medium business.

(8) HR Director. Large all-Russia company. Food retail.

(9) HR Director. International IT-company, Russian representative office.

(10) Deputy General Director for Legal Work. Large Russian IT company.

(11) IT Director. Russian engineering company, medium business.

(12) HR Director. Russian pharmaceutical company.

(13) Deputy General Director - Executive Director. Large Russian telecommunications company.

(14) Deputy General Director - Director for Organizational Development. Major Russian industrial company.

(15) HR Director. Russian IT company, medium business.

(16) Deputy General Director, HR-Director. International pharmaceutical company.

(17) IT Director. Regional company. Industrial production, medium business.

\section{REFERENCES}

Castells, M., A network theory of power. International Journal of Communication. Los Angeles (CA). 2011, Vol. 5, pp. 773-787.

Edmondson, A.C., Teaming: How Organizations Learn, Innovate, and Compete in the Knowledge Economy. Jossey-Bass, 2012.

Giddens, A., (1990) The Consequences of Modernity. Stanford University Press, Stanford, CA, 1990.

Hall, S., Encoding / Decoding. Media and Cultural Studies. Key Works / Ed. by M.G. Durham and D.M. Kellner. L.: Blackwell Publishers, 2001, pp. 163-173.

Schütz, A., Izbrannoye: Mir, svetyashchiysya smyslom [Selected writings: The world glowing with meaning]. Translated by V.G. Nikolayev, S.V. Romashko. ROSSPEN Publishrs, Moscow, 2004 (In Russ.)

Schütz, A., Some structures of the life-world. Voprosy sotsial'noy teoriyi. 2008, Vol. II. Iss. 1 (2). pp. 72-87. (In Russ.)

Seligmen, A., The problem of trust. Trans. from Eng. I.I. Myurberg, L.V. Soboleva. Ideyapress Publishers, Moscow, 2002. (In Russ.)

Shirokikh, E.A., Prichiny kommunikativnykh neudach $v$ internet-diskurse [Causes of communication failures in Internet discourse]. Vestnik Udmurtskogo universiteta. Series: Istoriya i filologiya, 2016, Vol. 26, Iss. 3, pp. 86-92. (In Russ.)

Sociology of a Pandemic. Proyect KoronaFOM. Head of the author's team: A. Oslon. InFOM, Moscow, 2021. (In Russ.)

Toshchenko, Zh.T., Zhiznenniy mir i yego smysly [The world of life and its meanings]. Sotsiologicheskiye issledovaniya, 2016, No. 1, pp. 6-17. (In Russ.)

Toshchenko, ZH.T., Zony uyazvimosti v prostranstve vozmozhnostey [Zones of vulnerability in the space of opportunities]. Readings from Yadov: Perspectives of sociology. Collection of scientific reports of the conference on December 14-16, 2015. Ed. by O. Bozhkov et al. EIDOS Publishers, St. Petersburg, 2016, pp. 182-191. (In Russ.) 